\title{
Ability to Determine the Quality of Indoor Air in Classrooms without Sensors
}

\author{
Tomasz Pietrucha ${ }^{1, *}$ \\ ${ }^{1}$ Laboratory of Sensor Technique and Indoor Air Quality Studies, Faculty of Environmental \\ Engineering, Wrocław University of Science and Technology, Wybrzeże Wyspiańskiego 27, 50-370 \\ Wrocław, Poland
}

\begin{abstract}
The search for new possibilities for assessing indoor air quality is one of the major challenges of our times. Results of many present investigations organized around the world indicates, that we are still not able to cope with inadequate air quality in many types of building. This fact results in a deterioration of occupants comfort and in the long time damage to health. For this reason indoor air quality in educational institutions deserves special attention. Children are more sensitive to contamination of indoor air and their ability to concentrate is dependent on the state of the air in the room, which affect later examination results. Considering the fact, that classrooms are used in a schematic way, in this paper it is proposed to use currently available calculation formula for determining the concertation of carbon dioxide, which is an indicator of indoor air quality. Results of calculations were compared with measurement data of carbon dioxide concertation collected in classrooms with natural ventilation. With appropriate data and assumptions calculation formula allow to determine the quality of indoor air in classrooms.
\end{abstract}

\section{Introduction}

Nowadays, keeping good indoor air quality in many types of buildings is the major challenge. Indoor air influence building occupant health, comfort and work productivity. Many studies are carried out in schools, because children are more sensitive for inadequate indoor air quality and they spend most of their day-time in classrooms. Children are particularly susceptible to indoor air pollution when compared to adults due to their underdeveloped immune and respiratory systems and high inhalation rates per body mass [1]. One of the first extensive studies to investigate indoor air quality in schools was carried out in Stockholm (Sweden) by Elias Heyman in the XIX century and the results were not satisfactory [2]. Now, many research in schools indicates that the problem of inappropriate indoor air quality still exists and it is spread around the world in developing and developed countries. For example in schools in Portugal [1], Japan [3], and Denmark [4]. In all of the works, authors claims that one of the problems is inefficient natural ventilation, which consists buoyancy-driven ventilation and ability of opening windows. Insufficient rates of fresh air supply to the classrooms are connected with inappropriate

*Corresponding author: tomasz.pietrucha@pwr.edu.pl 
indoor air quality, occurrence of SBS symptoms among pupils [3] and weaker results in the exam pass rates [5]. Natural ventilation types are common among schools. In practice they are very cheap in maintain, but they can't provide good indoor air quality when pupils are in the classroom. Because of all these evidences researches are looking for possibilities to provide good indoor quality in schools with natural ventilation. The best solution for this problem probably would be a mechanical ventilation, but it is very expensive. Moreover in many cases it could be impossible to mount mechanical ventilation, because of the structure of the building. Some curious idea was presented in publication [6]. Authors used carbon dioxide concertation as visual feedback for pupils. Carbon dioxide is usually used to investigate indoor air quality and rate of ventilation [7]. This compound is emitted from people during exhalation, and the emission rate depend on their activity [8]. Moreover, currently technology provides easy measurement of this gas [9]. Connection between carbon dioxide concentration and description of indoor air quality is presented on Table 1.

Table 1. Description of Indoor Air Quality on the basis of carbon dioxide concentration [10].

\begin{tabular}{|c|c|}
\hline Carbon dioxide concentration & Description of indoor air quality \\
\hline $350-400 \mathrm{ppm}$ & Fresh air, perfect conditions \\
\hline$<600 \mathrm{ppm}$ & $\begin{array}{c}\text { Acceptable conditions of indoor air quality in } \\
\text { rooms }\end{array}$ \\
\hline $1000 \mathrm{ppm}$ & The upper limit of fresh air \\
\hline $1500 \mathrm{ppm}$ & $\begin{array}{c}\text { People with respiratory illnesses may receive } \\
\text { cough, weakened people may faint }\end{array}$ \\
\hline $2000 \mathrm{ppm}$ & $\begin{array}{c}\text { Bad air quality causes increased breathing rates, } \\
\text { problems with respiration, headaches, nausea }\end{array}$ \\
\hline$>10000 \mathrm{ppm}$
\end{tabular}

Researches constructed special device, which indicates state of indoor air quality by green, yellow and red lamps on the basis of carbon dioxide concertation. Pupils were instructed how the device work and when they should open windows. Conclusions of this investigation shows, that visual information about indoor air quality for occupants results in improvement of indoor air quality in classroom. This method seems very promising, but still it needs founds and abilities, because this kind of device should be in every classroom in school. In this paper it is claimed, that to determine indoor air quality on the basis of carbon dioxide concentration there is no need of sensor. Concentration of carbon dioxide could be calculated using common known equation, but for that there are needed appropriate data. The problem of the data was considered in this paper.

\section{Experimental section}

Key to approach presented in the article are assumptions: I. Lessons are held in a schematic way. All pupils enter and leave the classroom at the same time. II. Fresh air in classroom is provided only by buoyancy-driven ventilation. III. Windows and doors of the classroom are closed during classes (which is normal situation, especially in cold months). IV. Before of each lesson classroom is properly ventilated by opening windows (carbon 
dioxide concentration in classroom is at outdoor level). Real-field measurements were collected in six classrooms in different schools. Schools were named from A to F. In every school was buoyancy-driven ventilation and openable windows. It was the only way to ventilate the room. Measurement were conducted in cold months, between November and March. Classes were held in the following manner: I. Before lesson classroom is properly ventilated by opening windows. II. Children enter the classroom - lesson begins. During class room is only ventilated by buoyancy-driven ventilation. III. Children leave the classroom. Classroom is ventilated by opening windows before next lesson (Figure 1.). Carbon dioxide was measured during all day, but for the later analysis were taken 45-minutes parts between entering and leaving the classroom by pupils. It was measured by nondispersive infrared sensor. The devices range was $0-5000 \mathrm{ppm}$, accuracy was $\pm 50 \mathrm{ppm} \pm 3 \%$ of measurement value and resolution was $1 \mathrm{ppm}$. The value was recorded every 1 minute. In three classroom (A, B and C) was measured amount of air exhausted by buoyancy-driven ventilation. On the basis of the data collected air exchange was calculated. Ventilation rate was measured by ventilation meter (anemometer) with flow hood two times per lesson. The devices range was $0.3-20.0 \mathrm{~m} / \mathrm{s}$, accuracy was $\pm 0.1 \mathrm{~m} / \mathrm{s} \pm 1.5 \%$ of measurement value and resolution was $0.1 \mathrm{~m} / \mathrm{s}$. Information about number of pupils was delivered from the teacher. Examples of equation to calculate concentration of carbon dioxide could be found in many publications $[11,12,13]$. In this work carbon dioxide was calculated using equation (1).

$$
C=[q /(n V)]\left(1-1 / e^{n t}\right)+\left(C_{0}-C_{i}\right) 1 / e^{n t}+C_{i}
$$

$\mathrm{C}$ is the calculated concentration of carbon dioxide [ppm], $\mathrm{q}$ is a emission of carbon dioxide $[1 / \mathrm{min}], \mathrm{V}$ is a volume of the room $\left[\mathrm{m}^{3}\right]$, e is a mathematical constant (2.718), $\mathrm{n}$ is an air exchange per hour $\left[\mathrm{h}^{-1}\right], \mathrm{t}$ is a time $[\mathrm{min}], \mathrm{C}_{\mathrm{i}}$ is a carbon dioxide concentration in outdoor air $[\mathrm{ppm}], \mathrm{C}_{0}$ is a carbon dioxide concentration in the room at start, $\mathrm{t}=0[\mathrm{ppm}]$.

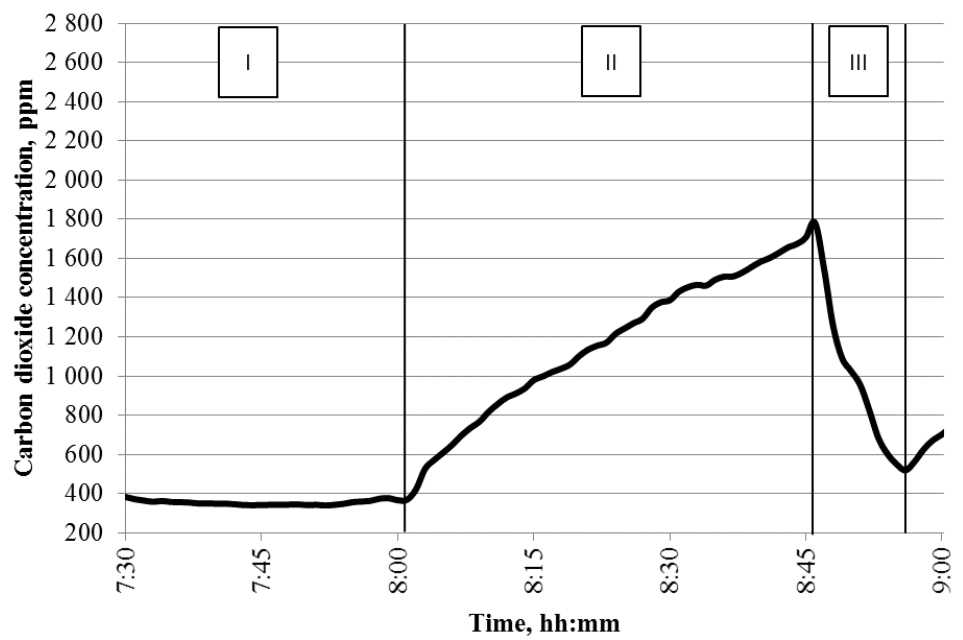

Fig. 1. Changes of carbon dioxide concentration and schedule of the measurement procedure during lessons: I. Before lesson classroom is properly ventilated by opening windows. II. Children enter the classroom - lesson begins. During lesson room is only ventilated by buoyancy-driven ventilation. III. Children leave the classroom. Classroom is ventilated by opening windows before next lesson. 


\section{Results and discussion}

Before calculating carbon dioxide concentration using equation (1) multiple data should be considered. Concentration of carbon dioxide in outdoor air varies from 350 to $450 \mathrm{ppm}$ [14]. For the calculation value of $400 \mathrm{ppm}$ was assumed. Information about emission of carbon dioxide from people could be find in publication [8]. Emission depends on people activity, so there was assumed that pupils' activity is between seated in quiet and office work. For calculations $0,27 \mathrm{l} / \mathrm{min}$ was adopted. Air exchange was calculated on the basis of measurement of air exhausted by buoyancy driven ventilation and volume of the classroom using equation (2), where $\mathrm{n}$ is an air exchange $\left[\mathrm{h}^{-1}\right], \mathrm{V}$ is a volume of the room $\left[\mathrm{m}^{3}\right]$ and $\mathrm{Q}$ is a mean rate of air exhausted by buoyancy driven ventilation in classroom $\left[\mathrm{m}^{3} / \mathrm{h}\right]$. Measurement of ventilation rates was performed 2 times per lesson (part II. from schedule). Mean value of ventilation rate for classroom A, B and C, calculated air exchange and air exchange assumed for calculation is presented on Table 2. Air exchange used in the formula for each classroom is a mean value of air exchange from school A, B and C.

$$
n=Q / V
$$

Table 2. Mean value of ventilation rate for classroom A, B and C, calculated air exchange and air exchange assumed for calculation.

\begin{tabular}{|c|c|c|c|c|}
\hline Classroom & $\begin{array}{c}\text { Volume } \\
{\left[\mathrm{m}^{3}\right]}\end{array}$ & $\begin{array}{c}\text { Mean rate of ventilation } \\
{\left[\mathrm{m}^{3} / \mathrm{h}\right]}\end{array}$ & $\begin{array}{c}\text { Air exchange } \\
{\left[\mathrm{h}^{-1}\right]}\end{array}$ & $\begin{array}{c}\text { Air exchange applied } \\
\text { to calculation formula } \\
{\left[\mathrm{h}^{-1}\right]}\end{array}$ \\
\hline A & 157,1 & 135.1 & 0.86 & \multirow{2}{*}{0} \\
\hline B & 215,1 & 204.3 & 0.95 & \multirow{2}{*}{0.75} \\
\hline C & 143,3 & 61.6 & 0.43 & \\
\hline D & 141,9 & - & - & \\
\hline E & 348,1 & - & - & \\
\hline F & 154,2 & - & & \\
\hline
\end{tabular}

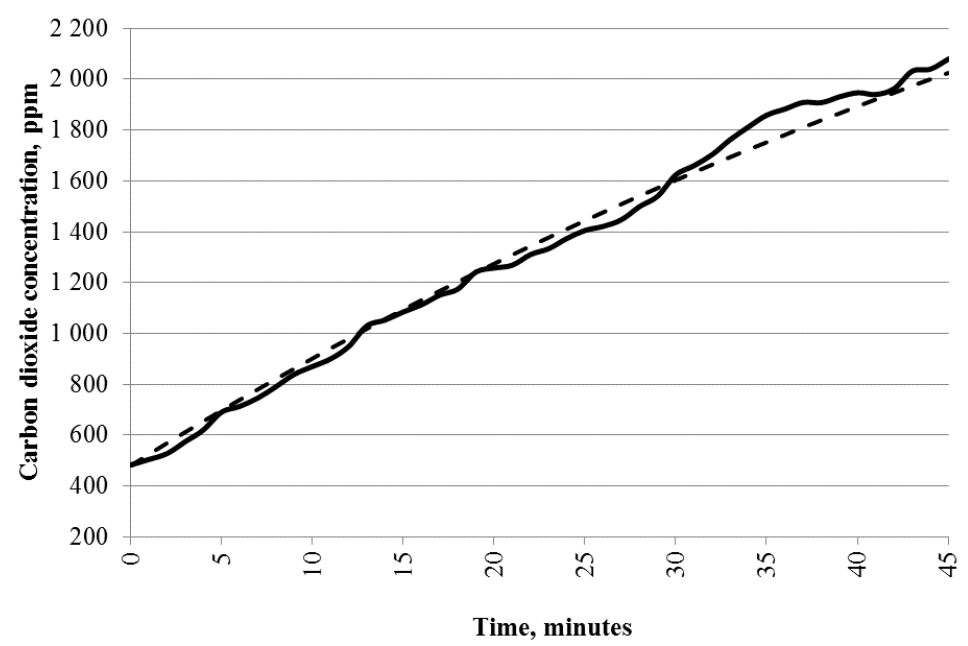

Fig. 2. Example of measured and calculated values of carbon dioxide in time during one lesson. Solid line - measured, dashed line - calculated. 
On the basis of upper assumptions carbon dioxide concentration was calculated and compared with 45 minutes carbon dioxide measurement parts (lessons) selected from daily measurement. There were selected 9 parts form school A, B $-5, \mathrm{C}-6, \mathrm{D}-8, \mathrm{E}-4$ and $\mathrm{F}-7$. Example of measured and calculated values of carbon dioxide in time during one lesson (45 minutes) is presented on Figure 2. Calculated and measured concentration was compared in two points: first point was in a minute, when measured value exceed $1000 \mathrm{ppm}$ and the second point was the forty-fifth minute of the lesson (end of the lesson). First point was usually achieved after 10-20 minutes of a lesson. Table 3 . presents values measured and calculated in these two points in school A. In the Table 4 there was checked, that the calculated concentration is in the range of measurement error of the measured value which corresponds. It is showed in percent. Moreover in the Table 5 there are mean values of the differences between calculated and measured concentration in ppm.

Table 3. Measured and calculated concentration of carbon dioxide in two comparative points (school A).

\begin{tabular}{|c|c|c|c|c|}
\hline \multirow{2}{*}{ Part } & \multicolumn{2}{|c|}{1000 ppm exceeded } & \multicolumn{2}{c|}{ End of the lesson } \\
\cline { 2 - 5 } & Measured & Calculated & Measured & Calculated \\
\hline 1 & 1029 & 1019 & 2080 & 2023 \\
\hline 2 & 1036 & 978 & 2022 & 2071 \\
\hline 3 & 1013 & 946 & 1761 & 1715 \\
\hline 4 & 1021 & 1038 & 1785 & 1959 \\
\hline 5 & 1010 & 1071 & 1895 & 2103 \\
\hline 6 & 1001 & 1063 & 1952 & 2244 \\
\hline 7 & 1014 & 956 & 1404 & 1394 \\
\hline 8 & 1009 & 914 & 1434 & 1322 \\
\hline 9 & 1019 & 1001 & 1635 & 1607 \\
\hline
\end{tabular}

Table 4. Number of cases when calculated concentration was in the error range of measured concentration.

\begin{tabular}{|c|c|c|}
\hline School & $1000 \mathrm{ppm}$ exceeded & End of the lesson \\
\hline A & $89 \%$ & $56 \%$ \\
\hline B & $80 \%$ & $60 \%$ \\
\hline C & $100 \%$ & $33 \%$ \\
\hline D & $88 \%$ & $75 \%$ \\
\hline E & $75 \%$ & $25 \%$ \\
\hline F & $71 \%$ & $71 \%$ \\
\hline
\end{tabular}

Key feature to assessing indoor air quality using this calculation formula are data and assumptions. Data like number of people, emission of $\mathrm{CO}_{2}$ from occupants or outdoor concentration of carbon dioxide are easy to get. The main problem could be the data about air exchange provided by buoyancy-driven ventilation in classrooms. On the basis of measurement from classrooms A, B and C mean value was calculated and it was $0,75 \mathrm{~h}^{-1}$. This data was applied and results were very positive. Most of the calculations was very similar to Figure 2. and these presented in Table 3., even in classroom D, E and F where 
was no data about air exchange. Measured and calculated concentrations were more similar in point when measured value exceed $1000 \mathrm{ppm}$ than in the end of the lesson which can be seen in Table 4. and Table 5.

Table 5. Mean difference between calculated and measured concentration in ppm.

\begin{tabular}{|c|c|c|}
\hline School & $1000 \mathrm{ppm}$ exceeded & End of the lesson \\
\hline A & 50 & 108 \\
\hline B & 29 & 111 \\
\hline C & 51 & 144 \\
\hline D & 48 & 61 \\
\hline E & 38 & 316 \\
\hline F & 71 & 85 \\
\hline
\end{tabular}

This is very promising, because when concentration of $\mathrm{CO}_{2}$ raise $1000 \mathrm{ppm}$ proper actions should be taken to improve indoor air quality. Classroom $\mathrm{E}$ is designed for 90 occupants and the rest of the classes for 20-30 pupils. Calculated concentration in 3 of 4 cases in this classroom was in the error range of measured concentration and the mean difference was only $38 \mathrm{ppm}$. It can be said that this calculation of carbon dioxide could be applied in different size classes. Moreover that rate of exhausted air provided by buoyancy-driven ventilation in schools was very similar and lack of knowledge about rate of ventilation is not a problem to determine indoor air quality on the basis of calculated carbon dioxide concentration. But this method is only usable under assumptions given in Experimental section. Without this foundations it is impossible to use this method to determine indoor air quality. Comparing this method with the method described in the publication [6], for determining the concentration of $\mathrm{CO}_{2}$ with appropriate assumptions and data do not need a $\mathrm{CO}_{2}$ sensor. This is very huge advantage of this method and because of that it could be applied in every school with natural ventilation, for example an application for a smartphone.

\section{Conclusions}

There could be drawn the following conclusions: (1) If lessons take place in accordance with the assumptions it is possible to determine the concentration of $\mathrm{CO}_{2}$ in the air which will provide information about indoor air quality. (2) In most cases at the point when $1000 \mathrm{ppm}$ was exceeded, differences between calculated and measured $\mathrm{CO}_{2}$ concentration do not exceed the error of measurement device (3) The differences was higher at the end of the lessons but classroom should be ventilated before carbon dioxide concertation exceed $1500 \mathrm{ppm}$ (Figure 2. and Table 3.).

The conference participation was financed from the statutory funds of Faculty of Environmental Engineering, Wrocław University of Science and Technology from the project 0401/0066/16.

\section{References}

1. J. Madureira, I. Pacienecia, C. Pereira, J. P. Teixieira, E. de O. Fernandes, Indoor air quality in Portuguese schools: levels and sources of pollutants, Indoor Air 26, 526-537 (2016) 
2. J. Sundell, On the history of indoor air quality and health, Indoor Air 14, 51-58 (2014)

3. M. Takaoka, K. Suzuki, D. Norback, Sick Building Syndrome among Junior High School Students in Japan in Relation to the Home and School Environment, Global Journal of Health Science, Vol. 8 No. 2 (2016)

4. D. Wyon, P. Wargocki, J. Toftum, G. Clausen, Classroom ventilation must be improved for better health and learning, REHVA. Eur. HVAC. J., 3, 12-16 (2010)

5. M. J. Mendell, E. A. Eliseeva, M. M. Davies, A. Lobschied, Do classroom ventilation rates in California elementary schools influence standardized test scores? Results from a prospective study, Indoor Air 26, 546-557 (2016)

6. P. Wargocki, N. A. F. Da Silva, Use of visual CO2 feedback as a retrofit solution for improving classroom air quality, Indoor Air 25, 105-114 (2015)

7. A. Szczurek, M. Maciejewska, T. Pietrucha, CO2 and volatile organic compounds as indicators of IAQ, 6th AIVC Conference, 5th TightVent Conference, 3rd venticool Conference, Madrid, Spain 23-24 September 2015

8. D. S. Dougan, L. Damiano, CO2-based demand control ventilation do risks outweigh potential rewards?, ASHRAE Journal 46 (2004)

9. N. Mahyuddin, H. B. Awbi, A review of CO2 measurement procedures in ventilation research, International Journal of Ventilation 10, 353-370 (2012)

10. T. Pietrucha, Measurement of carbon dioxide concentration for assessment of indoor air quality in the lecture hall, 13th Students' Science Conference, Polanica-Zdrój Poland, 17-20 September 2015

11. http://www.engineeringtoolbox.com/pollution-concentration-rooms-d_692.html [on-line: 25 January 2017]

12. P. Kapalo, S. Vileckova, F. Domnita, O. Voznyak, Determine a methodology for calculating the needed fresh air, The 9th International Conference “ENVIRONMENTAL ENGINEERING”, Vilnius Lithuania, 22-23 May 2014

13. D. Kosicanova, R. Nagy, I. Senitkova, Transmission and distribution of pollutants in relation to the environment, Technical University of Kosice (2011), ISBN 978-80-5530829-6

14. A. P. Jones, Indoor air quality and health, Atmospheric Environment 33, 4535-4564 (1999) 